\title{
Traducción y anotación "filológica": calas en la poesía
}

\author{
DAVID GARCíA PÉREZ \\ Centro de Estudios Clásicos, IIF \\ Universidad Nacional Autónoma de México \\ hyperion0z@yahoo.com
}

Recibido: 8 de noviembre de 2012

Aceptado: 3 de marzo de 2013

\section{RESUMEN}

Este trabajo explora algunos ejemplos de traducción de poesía griega antigua, a fin de reflexionar sobre los distintos cambios y modos de recepción del contenido poético, así como la función de la nota "filológica" que busca hacer comprensible la traslación de la poesía en cuestión.

Palabras clave: estudio de traducción, anotación filológica, poesía, Grecia antigua.

Translation and "Philological" Notes: Some Examples in Poetry

\begin{abstract}
This work explores the translation of some examples of the ancient Greek poetry. The focus point is the thought about the different changes and modes of poetics comprehension, as well as the purpose of the "philological" note, whose end is the understanding of the poetry.
\end{abstract}

Keywords: Translation Studies, philological notes, poetry, ancient Greece.

Sumario: 1. Introducción. 2. Calas en la poesía homérica. 3. Ejemplo de anotación "filológica”. 4. Otras calas en la poesía griega antigua. 5. Conclusión.

\section{Introducción}

La jerarquía que los griegos de la antigüedad otorgaban a la palabra, que discurre de su aspecto divino y mágico a la persuasión mediante el argumento retórico, y de su poder curativo a la catarsis de la poesía, edifica por esta cualidad específica 
una especie de halo absoluto que hace de la tarea de la traducción de los textos clásicos en general, de la poesía en particular, un ejercicio que pende siempre de la corrección propia de la tradición clásica y, específicamente, de la filología. Ya Gorgias de Leontinos (c. 480 a. C.) argumentaba que "nada es ... que aunque sea, es incognoscible para el hombre y... aunque sea cognoscible es incomunicable e inexpresable a los otros" (Sext., Adv, math. VII 65: 82B3 DK), tal pensamiento aplicado a un proceso de traducción implica aquello que Benedetto Croce sostenía acerca de la imposibilidad de verter contenidos literarios de una lengua a otra como una consecuencia propia de la naturaleza del lenguaje: "ogni espressione è un'unica espressione" (Croce 1928: 23). A tal cualidad de su "naturaleza" hay que sumar la observación de los códigos que rigen al lenguaje. En efecto, si ya los primeros gramáticos enmendaban la plana de Homero con criterios a veces no muy convincentes, qué se puede esperar como traducción de aquello que, tomando en el mejor de los casos una edición autorizada, resulta para lectura de un determinado público. $\mathrm{La}$ traducción de los clásicos pasa por la herencia lingüística de la palabra, entendiendo por esto el cuidado que se tiene de la corrección a partir de los códigos que rigen a las lenguas clásicas y la preservación de los contenidos de acuerdo con una reconstrucción del contexto. Entre estos dos puntos oscila el resultado de la traducción: o bien produce un texto que traslada palabra por palabra los equivalentes entre la lengua de partida a la de llegada y que por este proceso se pierde el contenido, o bien resulta un texto en el que el griego queda disipado en cuanto a los componentes retóricos y poéticos que lo definen como lengua literaria. A lo largo de un punto y de otro, se pueden encontrar las más variadas intenciones de traducción y en ello radica la riqueza de la interpretación del texto fuente. Cada vez que se traduce, se elige en cada palabra un modo de recepción; de esto se sigue que la traducción es también una relectura íntegra para trasladar a su aquí y ahora los contenidos de otro tiempo y espacio:

Al principio de la traducción está la palabra escrita; al principio de la interpretación, el discurso oral. En aquélla, según parece, predomina la creencia mítica de que conocer el verdadero nombre significa tener el dominio sobre la cosa nombrada; ésta, por el contrario, más bien parece asunto de negocios y de comercio. La interpretación se atiene a la fidelidad al sentido del discurso; la traducción, a la de la palabra. El traducir literalmente, al principio, tal vez puede explicarse por el júbilo que debió producir el descubrimiento por la palabra. (Tapia Zúñiga 1996: 31)

De acuerdo con lo anterior, la traducción es algo propio del texto escrito, en razón de que no hay interpretación porque no se tiene a disposición las inflexiones propias del autor del texto fuente. Si esto es así, cuando se habla de traducción de un texto poético, la tarea también reside en captar los motivos, el contenido, la intención de la poesía, y todo ello guardando relación con la cualidad musical de los versos. Es por ello que interesa reflexionar sobre la traducción de la poesía griega; no pretendemos hacerlo desde una postura teórica de quien sabe el oficio de la traducción, sino del receptor que acude a ésta para poder acceder a un universo poético, cuyos registros son en muchos sentidos distintos de acuerdo con el modo de recep- 
ción. El lector asume el texto traducido como el objeto en sí de la transmisión de un universo de ideas, de modo que aquél crea los referentes culturales, cualesquiera que sean sus características, del campo de la lingüística a la de la construcción de un imaginario. Como vehículo y como puente, la traducción de la poesía griega antigua es en la mayoría de los casos, la única vía para acceder a aquel mundo remoto. De las cualidades de la traducción depende en gran medida la edificación sólida del imaginario al que hacemos referencia.

\section{Calas en la poesía homérica}

Pongamos por caso el epíteto, rasgo estilístico que define estéticamente la poesía homérica. El epíteto resulta en ciertos casos la seña de identidad del personaje o el objeto que lo recibe. Hay epítetos que pueden ser comunes, compartidos por un conjunto de personajes o de objetos, pero otros no son supletorios; al contrario, a la vez que marcan la depuración del adjetivo al hacer de él en sí mismo una definición metafórica, también funcionan como rúbrica de la nemotecnia, del color y del ritmo propios todos ellos de la poesía oral. Así, el consabido ejemplo "Aquiles, el de los pies ligeros" (Пó $\delta \alpha \varsigma$ $\grave{\chi} \chi \grave{v} \varsigma$ 'A $\chi 1 \lambda \lambda \varepsilon v$ v́s), es una fórmula que resulta tan naturalmente fija que no difiere en las traducciones al español más conocidas. Los traductores renuncian a traducir, por variar, imágenes como "el de pies volátiles", "el de veloces pies" o, simplemente, "el velocípedo".

Sin embargo, en otros casos, la innovación del traductor hace dudar del mismo texto homérico, si se piensa, como pasa con la poesía homérica, en que en la traducción hay una tradición, esto es, el público lector está acostumbrado a ciertas construcciones referentes al imaginario homérico del mismo modo como lo estaba el receptor de griego de la antigüedad, tal como Aristóteles lo consigna al reprobar aquellos epítetos metafóricos que pretendían suplir a "la aurora de rosáceos dedos", por otro color que no fuera éste: "la aurora de rojos dedos", por ejemplo (Arist., Rhet. 1405b18-20). Es notorio, por citar un caso, que la adjetivación de Apolo más socorrida es la de "el flechador", que es la que se lee en la traducción de Luis Sega-

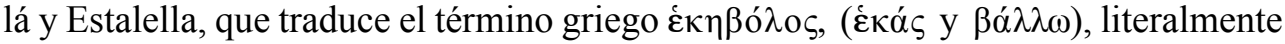
"el que arroja desde", y lo que dispara Apolo, sabemos, son sus flechas, de ahí que el traductor concentre en "flechador" el adverbio y el verbo que conjuntan el sentido de ambas palabras. En la traducción de Rubén Bonifaz el lector encuentra un tér-

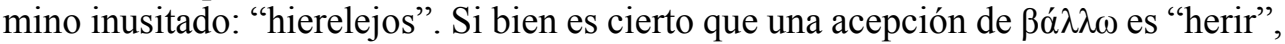
ésta se halla en un tercer o cuarto lugar en cuanto al contenido registrado en los diccionarios. Por otra parte, el epíteto propuesto por Bonifaz pone el acento en la acción de herir, no en el de arrojar las flechas; así, la diferencia semántica es notoriamente distinta, pues la imagen poética en el receptor difiere en cuanto a la acción indicada. Segalá y Estalella acertadamente coloca el sentido en la acción que ejecuta el dios $(\beta \alpha \dot{\lambda} \lambda \omega)$; a Bonifaz se le escapa el matiz y prefiere el resultado de la acción a través de otro verbo ,"herir", que no está expresado en $\dot{\varepsilon} \kappa \eta \beta$ ó $\lambda$ os.

Para el griego antiguo las fórmulas homéricas eran percibidas sin mediar una interpretación, tal como sucedería con cualquier lengua cuyo sistema de construc- 
ción poética fuera oral; lo anterior no deja de ser una noción relativa, sobre todo si se habla de poesía, pues este tipo de discurso es de suyo polisémico. Si esto es así, ¿cuál de las posibilidades semánticas es la que priva, bajo qué criterio?, ¿qué componentes seleccionados entrar en juego para determinar la traslación de dicha imagen a la lengua de llegada?

Que las imágenes poéticas responden al imaginario del contexto más que del poeta, o bien éste las construye a partir de lo que recoge de su contexto, queda claro en la explicación de Aristóteles al referirse al epíteto metafórico ya referido: "aurora de rosáceos dedos" ('Hஸ̀ decir: "aurora, la de rosados dedos" mejor que "la de purpúreos dedos"; y todavía estaría peor "la de rojos dedos". ${ }^{1}$

El caso propuesto por Aristóteles es un epíteto de la poesía homérica (Hom., Il. I 477; VI 175; IX 705). Lo que el estagirita sugiere es que hay una diferencia semán-

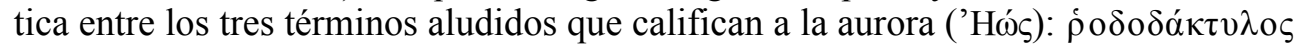

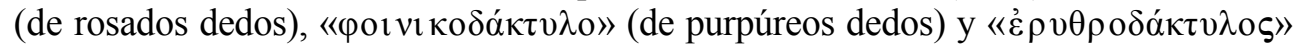
(de rojos dedos). Sin embargo, tal diferenciación parte de un supuesto: el modelo poético heredado por Homero, es decir, que la metáfora que alude a la aurora ha sido ya establecida tanto por la repetición, como por el simbolismo del epíteto. En efecto, un rasgo característico del epíteto es el hecho de que por su carga semántica como por su uso continuo puede sustituir a su referente; así cuando se dice "la de rosados dedos", no es necesario nominar a la aurora dado el contexto en el que se produce y reproduce la metáfora. $\mathrm{Y}$ es esta misma carga semántica lo que hace que se elabore un signo. Otro ejemplo, decir "el astro de otoño" (Hom., Il. V 5) para referirse a la estrella Sirio, tanto por la repetición como por su sentido se trata de una probabilidad y de un signo.

Hay que observar también que el ejemplo de Aristóteles está dispuesto de forma

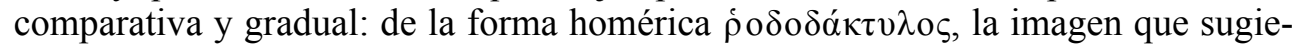
re la metáfora decae en el segundo y tercer términos, tal como se especifica por

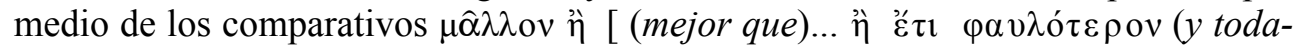
vía...peor). De acuerdo con la tradición poética que recoge el estagirita, se puede decir que pasa a significarla de manera proverbial, mientras que para los otros dos términos se puede aplicar lo que en Tópicos se define como nombres "no establecidos" ( $\mu$ ì

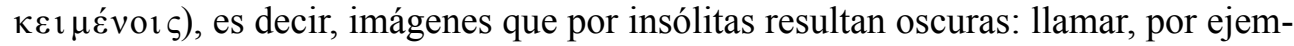
plo, a la tarántula "la de mordedura putrefaciente" (Arist., Top. 140a 3-5). Se entiende que tal imagen no pertenece al imaginario colectivo, por lo que resulta una metáfora exótica.

La metáfora, entonces, proyecta un sentido que forma parte de la producción poética común, pues atrae una serie de símbolos, los hila de modo analógico para que uno de los elementos metafóricos quede bajo la sombra de la duda. En este sen-

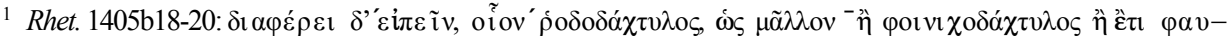
$\lambda o ́ \tau \varepsilon \rho$ ov $\varepsilon \rho v \theta \rho o \delta \alpha ́ \chi \tau v \lambda o \varsigma$. Hay que observar que la teoría aristotélica considera al epíteto dentro de la metáfora.
} 
tido tal vez sea posible decir que el enigma forma parte de los ejemplos y de las máximas, pues sólo quien es capaz de hallar el elemento faltante puede alcanzar el cabal entendimiento. Esto último plantea una serie de cuestiones por resolver siempre que se ejercita su correspondiente traducción.

Dejando de lado el epíteto que es una fórmula poética bien caracterizada en Homero, hay palabras que algunos traductores quizá buscan actualizar, pero el resultado conduce nuevamente a otra imagen diferente a la del texto fuente. Veamos un caso sencillo en Odisea IV 17-19, en la descripción del palacio de Menelao y de lo que ahí sucede:

Un aedo divino cantaba entre ellos tañendo su gran lira y un par de payasos hacían cabriolas en la mitad del salón...

Sólo se hará referencia a un término que puede resultar difícil para imaginar dicha escena: la palabra $\kappa \nu \beta \iota \sigma \tau \eta \tau \hat{\eta} \rho \varepsilon$ refiere al acróbata, al saltimbanqui, a alguien que salta, pero no a un payaso. La semántica de tal palabra en el español común apunta a lo que consigna el DRAE: "artista de circo que hace de gracioso, con traje, ademanes, dichos y gestos propios", y de ahí que como adjetivo se refiera a la persona "de poca seriedad, propensa a hacer reír con sus dichos o hechos." Así pues, el lector común, el que no consulta el texto griego (para eso está la traducción) se queda con la imagen del payaso de circo y no con la del acróbata (que también es una palabra griega), tal como se sugiere y se comprueba un significado distinto en la plástica.

Como se puede observar en lo ejemplificado, el traductor recurre a la expresión poética de su propia lengua para rescatar el sentido poético y en otro casos, busca actualizar los contenidos con términos que no caben en el texto fuente, haciendo de ello una especie de anacronismo. A este respecto, dice Crespo Güemes:

Cuando es posible la correspondencia entre la lengua fuente y la lengua receptora, en una traducción literal de una obra en la que los aspectos formales no carecen de importancia, podemos esperar que un mismo término reproduzca siempre el mismo vocablo y que haya un sólo término para cada expresión. (1991: 102)

Tal afirmación vale para una poesía como la homérica en la que el sistema formular espera en su traducción una expresión que resguarde la intención estilística, esto es, la fortaleza épica de cada una de las imágenes que, una vez fijas, tiene un equivalente con el texto fuente. Si hay una economía formular en la poesía homérica, el traductor debe respetar las cualidades más elementales de dicho concepto, entre ellos el de la repetición. A propósito de esto, acudimos al siguiente caso que, además, comentamos por sus cualidades estéticas.

Cuando Patroclo muere, lleva puestas las armaduras de Aquiles. No es él en verdad quien lucha y a quien la muerte en forma de Héctor persigue. Pero el destino está marcado y debe fenecer. Patroclo fallece bajo el influjo de una ilusión. Cuando Héctor marcha para encontrarse frente a frente con Aquiles, tiene la certeza de que es su destino el que lo conduce a tal encuentro, al grado de rechazar las palabras de 
Príamo, su padre, de que se ponga a salvo tras las puertas de Troya. Héctor sí es él mismo, a diferencia de Patroclo, pero la ilusión también lo hace su presa y cree poder vencer a Aquiles, para luego sólo darse cuenta de que los dioses han decidido ya su suerte final (Il. XVI 855-857 y XXII 361-363).

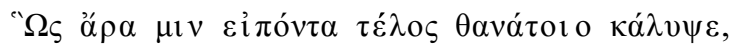

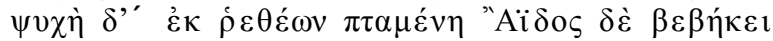

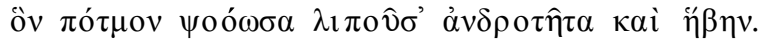

Como se puede observar, el poeta usa la misma fórmula para indicar el momento preciso en que la muerte cae sobre los dos héroes. Esta es nuestra traducción:

Luego de que así habló, el fin de la muerte lo arropó y su alma, habiendo volado de sus miembros, llegó al Hades, su destino lamentando, pues abandonaba su varonil juventud.

En efecto, Homero, como hemos dicho utiliza los mismos versos para describir el último aliento tanto de Patroclo como de Héctor. Sin embargo, en la traducción de Bonifaz Nuño, se lee una traducción distinta para cada pasaje, siendo que los versos homéricos son idénticamente los mismos; en Hom., Il., XVI 855-857:

En diciendo el así, lo envolvió el fin de la muerte, y el alma, de sus miembros habiendo volado, fue al Hades, llorando su suerte, tras dejar plenitud y verdor.

Y en XXII 361-363 así traduce Bonifaz:

A él, que había dicho así, lo envolvió el fin de la muerte, y el alma, en volando de sus miembros, fue a lo del Hades, llorando su destino, dejando robustez y verdor.

Como vemos, los tres hexámetros traducidos tienen variaciones. Si bien se conserva la idea general, los matices denotan cambios en el cuadro homérico: por ejemplo, el matiz temporal que indica la sucesión inmediata de hablar y morir, no se aprecia en la segunda traducción, pues se da como un hecho puntual junto a otro del mismo matiz, pero sin marcar que al momento de terminar de hablar, la muerte cae sobre Patroclo. El siguiente verso presenta un juego al cambiar el lugar de las palabras y en usar el consabido gerundio para traspasar un participio. $\mathrm{Y}$ en el tercer verso citado, el término $\pi$ ó $\tau$ oov es visto como "suerte" y como "destino", sin mayor detenimiento en el vocabulario homérico que es semánticamente rico para determinar la idea del sino; y llama la atención también en este

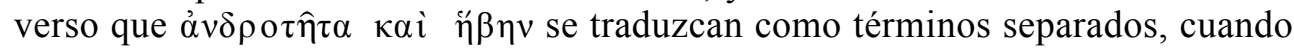
el primero puede ser un adjetivo del segundo término. Y no se puede dejar de lado que $\dddot{\beta} \beta \eta \nu$ es, de modo directo "juventud", cualidad del ser joven y lo que ello implica, pero "verdor" puede ser tomado como un arcaísmo; el público no comprendería que tal coloración es propia del vivo término $\alpha \nu \delta \rho o \tau \tilde{\eta} \tau \alpha$, viril, y no 
que se hace referencia a ese color sin conexión clara con algún otro elemento que aparezca en los tres versos citados. Este uso arcaico se comprueba en otra traducción de Bonifaz, la Pítica VII de Píndaro, donde leemos:

... con benigno ánimo

de Jenarces, desde Cirra, al hijo recibió coronado

de la verdura parnasia y la dórica pompa

"Verdura" es la traducción para $\pi$ ó $\alpha$ que es más bien follaje y, en relación con

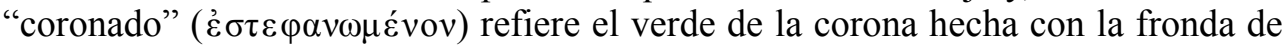
diversas plantas y/o árboles; pero la juntura "coronado de verdura" nos parece una imagen poco afortunada para indicar la preeminencia del triunfo y, por extensión, de la fertilidad. La imagen sugerida en la traducción puede resultar, incluso, cómica: el héroe vencedor llevando "verdura" del Parnaso en su cabeza.

Volviendo al pasaje homérico, vemos también algunos cambios en la traducción de Crespo Güemes. En el primer caso, tenemos la siguiente traducción:

Apenas hablar así el cumplimiento de la muerte lo cubrió.

El aliento vital salió volando de sus miembros y marchó al Hades

llorando su hado y abandonando la virilidad y la juventud.

Para el segundo momento, se lee

Apenas hablar así, el cumplimiento de la muerte lo cubrió.

El aliento vital voló de la boca y marchó a la morada del Hades,

llorando su hado y abandonando la virilidad y la juventud.

En este caso, la imagen de que el aliento vital vuela de la boca sustituye sin ninguna justificación el término "miembros" ( $\dot{\varepsilon} \kappa \hat{\rho} \varepsilon \theta \dot{\varepsilon} \omega v)$ por "boca"; en este caso, el traductor ha optado por una imagen más común en la literatura escrita en español ${ }^{2}$.

\section{Anotación "filológica"}

Hemos escrito anotación "fillológica" entrecomillada la última palabra por el desconcierto que pueden causar las notas que refieren todo tipo de información respecto del texto fuente y de su traducción, notas que abarcan el trabajo de edición, de crítica textual, de comentario filológico, etcétera. Tales notas, viéndolas de este modo, llegan a ser un apéndice o extensión de la traducción, pues lo que buscan, en general, es ofrecer una explicación mayor al lector para una comprensión más acabada del texto (de ambos textos). Si la traducción debería tener un referente especí-

${ }^{2}$ La traducción de Luis Segalá sí repite la misma traducción, como creemos que debe ser, en ambos casos: "Apenas acabo de hablar, la muerte lo cubrió con su manto: el alma voló de los miembros y descendió al Orco, llorando su suerte porque dejaba un cuerpo vigoroso y joven." 
fico a fin de establecer los puentes de traslación más adecuados, las notas obligatoriamente estarían pensadas para acotar lo que se busca que el receptor conozca a partir de lo traducido. Hay notas, incluso, que explican el sentido de la traducción, esto es, la elección de tal o cual término frente a otros con la finalidad de justificar en el texto de llegada.

Veamos un ejemplo tomado ahora de la tragedia griega. En los versos 3-6 del Prometeo encadenado de Esquilo leemos:

Hefesto, justo ahora ocúpate de las órdenes que te impuso tu padre, que en rocas de altas peñas a este bandido sujetes con irrompibles grilletes de adamantinas cadenas.

$\mathrm{Y}$ ensayemos una nota para el adjetivo adamantino:

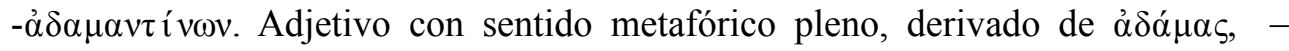
$\alpha v \tau$ os. El término aparece en Hes., Theog. v. 161, a propósito de la emasculación de Urano, para referirse a la naturaleza de un metal que es parte de la propia expresión poética. En efecto, para que Cronos pudiera llevar a cabo tal hazaña, debía contar con una hoz hecha de ese material, como se infiere del v. 188. El adjetivo que denota la dureza de tal material funcionó también para referirse a los sentimientos, como en Theog. v. 239, donde se lee que Euribia... corazón de adamante tiene en el pecho. Cfr. Paola Vianello, en Hesiodo. Teogonía, n. 161, p. CCCXVIII. Los hombres de la raza de bronce también tienen el corazón de adamante (Erga, v. 147), lo

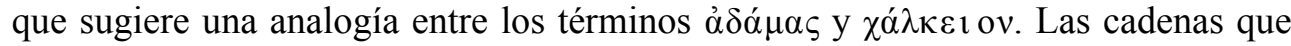
ataban al Titán eran, entonces, inquebrantables, al punto que ni él mismo podía libe-

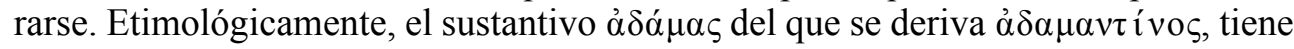
por tema $\delta \alpha \mu \alpha-$, del verbo $\delta \alpha ́ \mu v v \mu$ (domar, vencer, sojuzgar; vid. supra n. v. 5), de ahí que las cadenas con las que Prometeo es atado denotan de manera directa la dureza propia del material con el que están hechas y, al mismo tiempo, está implícita la idea de que sirven para domar a Prometeo, pues el tema y sus compuestos eran usados propiamente para referirse a la domesticación de los animales. Así, ŠdamantínoV es un término metafórico en el contexto dispuesto por Esquilo a propósito de la violencia ejercida contra Prometeo.

Como se observa, la nota referida a un solo término abunda en información para que el lector aprecie que las cadenas que atan a Prometeo son de tal dureza que no podría romperlas, como en efecto sucede. El término traducido es un calco al español, pero se halla en desuso, a decir del DRAE. La evolución de adamante dio al español la palabra diamante, por lo que cabe la traducción "diamantinas cadenas", lo que en la recepción común daría como imagen unas cadenas "brillantes" (como

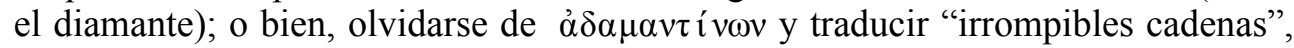
que es lo que esencialmente expresa el término y que el lector común puede entender claramente. Pero el poeta, que no quiere repetirse, y como pensaba que lo fuesen a traducir al español escribió en el v. 19-20: "con broncíneas cadenas irrompi-

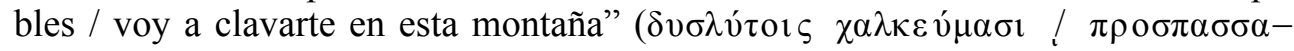




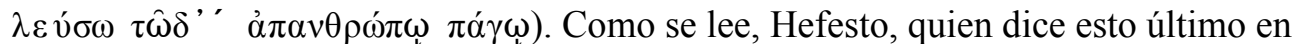
la tragedia referida, quiere corregir a Cratos y dice que sí va a atar a Prometeo con cadenas irrompibles de bronce, es decir, una imagen sinónima de aquellas adamantinas. Pero lo que se quiere marcar aquí es el uso del término $\delta v \sigma \lambda v ́ \tau o ı \varsigma$, que aquí se ha traducido por "irrompibles", de modo que la tercera opción de traslación apuntada arriba para indicar lo adamantino como irrompible, indestructible, ya no opera en razón de la especificidad del poeta en este segundo caso.

En el ejemplo de nota filológica encontramos información retórica: "adjetivo con

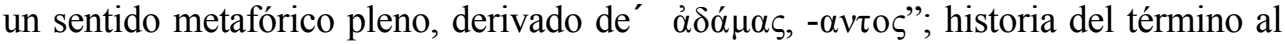
referirlo a Hesíodo, donde, a su vez, se comenta en sentido poético: los sentimientos adamantinos de Euribía, es decir, duros, inquebrantables e información etimológica.

Pues bien, si un alto porcentaje de notas de este tipo (en otras aparecerían los datos estrictamente filológicos), aparece en un poema que consta de 1092 versos, la lectura que sea no de otra índole sino de la literaria, porque esa es su naturaleza, se topará con una suerte de digresiones que, si bien nutren la especificidad de los contenidos del poema para la comprensión cabal del lector, también lo es que el aspecto literario (la estética literaria) queda disminuido sensiblemente, por decir lo menos. Como se ha venido diciendo, la traducción y lo que la adereza, en este caso las notas, considera necesariamente al receptor: ¿para quién se traduce y para quién se hace la anotación?

\section{Otras calas en la poesía griega antigua}

Aristófanes es uno de los poetas griegos que ofrece gran dificultad para la traducción, pues no acepta la literalidad y tampoco cabe en ella la interpretación que , como sucede en la versión de Ángel María Garibay, lleva por muy diferentes derroteros semánticos la comicidad política y sexual de la comedia. Y no hay literalidad posible porque el humor que se produce a través de los ingredientes lingüísticos propios del griego ático son incontestables en el español, de ahí que si, por ejemplo, los compuestos aristofánicos se traspasan al español se corre el riesgo de dejar en el camino el objetivo de la comedia, es decir, la risa; de modo contrario, cuando se busca el rescate de la esencia cómica mediante giros y rebuscamientos propios de la lengua de llegada, de igual manera, el texto se torna pesado (frente a la agilidad de Aristófanes) y la risa se pierde. En este sentido, vale la pena recuperar lo siguiente:

noi traduciamo sempre, perché la lingua, non quella delle grammatiche e dei vocabolari, ma la lingua sonante nell'animo non è mai la stessa, né anche in due istanti consecutivi, ed esiste a condizione di trasformarsi continuamente inquieta e viva. (Gentile 1920: 370)

de modo similar, pero con mayor claridad apuntó Octavio Paz:

Aprender a hablar es aprender a traducir; cuando el niño pregunta a su madre por el significado de esta o aquella palabra, lo que realmente le pide es que traduzca a 
su lenguaje el término desconocido. La traducción dentro de una lengua no es, en ese sentido, esencialmente distinta a la traducción entre dos lengua y la historia de todos los pueblos repite la experiencia infantil. (Paz 1971: 7)

A nuestro juicio, las distintas traducciones de la antigua poesía griega apuntan de modo general, y como es de esperarse, a la conservación del tema y de los tópicos centrales que la conduce. Pero al ser la poesía un texto polisémico y, al mismo tiempo, preciso en la definición de los componentes de su estilo, en ciertos momentos hay referentes distintos, si se comparan dos o más traducciones del mismo texto fuente. El método de traducción elegido, la finalidad de ésta, así como las posibilidades artísticas del traductor son determinantes para la apreciación del poema traducido. No compartimos la idea de que sólo el poeta puede traducir a otro poeta. Hay casos desafortunados como traducción, pero afortunados como recreación del motivo lírico, por ejemplo, si pensamos en las poéticas interpretaciones de la poesía de José Emilio Pacheco y de Rubén Bonifaz. Veamos un sólo caso en el que Safo dice:

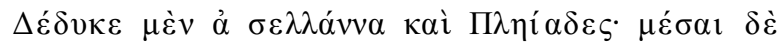

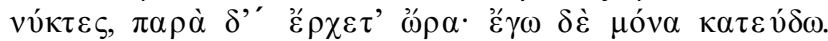

La traducción de Montemayor es:

Se han puesto la luna y las Pléyades ya es media noche; las horas avanzan, pero yo duermo sola.

La traducción de José Emilio Pacheco es:

Se fue la Luna.

Se pusieron las Pléyades.

Es medianoche.

Pasa el tiempo.

Estoy sola.

Y finalmente Bonifaz tradujo:

Se pusieron, pues, la luna y las Pléyades. Y medias noches. Y resbala el tiempo Y yo estoy sola acostada.

Una simple y detenida lectura indicaría imágenes poéticas distintas en las tres versiones. La sintomatología de la soledad que padece la poeta en la noche difiere sustancialmente en las traducciones. Y hay que volver al texto original para captar la profundidad con la que Safo encabalga cada uno de los términos mediante relaciones analógicas que apenas se advierten en los tres casos de traslación aludidos. Ejemplifiquemos mediante un sólo rasgo: la traducción de Bonifaz es literal en los nexos que aparecen en el texto griego $(\mu \dot{\varepsilon} \nu \ldots . . . \quad \kappa \alpha \grave{i} . . \quad \delta \dot{\varepsilon} \ldots . \quad \delta$ '... $\delta \grave{\varepsilon}$ : pues... y... Y... Y... Y), en comparación con la versión del poeta José Emilio Pacheco que le imprime un ritmo diferente al evitar todos los nexos y traducir secuencial y paratácticamente. 
Montemayor, por su parte, sólo tradujo el nexo, кaì, y obvió los demás, creando una ambigüedad en la sucesión de las imágenes, si se piensa en la construcción del original. De este modo, el receptor de las tres versiones tiene ante sí tres cuadros diferentes en los que la profundidad, el color y la percepción de la poesía sáfica sólo queda en el contenido.

\section{Conclusión}

Como se ha podido observar, la traducción de la poesía griega requiere de la reconstrucción de un universo poético con sus imágenes, con la inmersión en un imaginario que resulta sumamente difícil de trasladar del griego antiguo al español, de modo que se conserve el contenido, las cualidades estilísticas, la construcción retórica, etcétera. En los ejercicios de traducción de los ejemplos que aquí se han tratado, se aprecia la recepción peculiar que cada traductor construye y su manera particular de proyectar el original. Si la lectura de la poesía es ya de suyo una "traducción" dentro de una misma lengua, cuando se habla de la traducción de una lengua a otra los niveles de comprensión estética son tan variables y profundos como lo es también la comprensión sociolingüística de los contenidos. Las notas, por otra parte, constituyen otro texto dentro del texto, de hecho se puede pensar que se trata de todo un género del lenguaje, pues en ellas se atiende la comprensión integral del contexto. Pero precisamente por ello, la anotación "filológica" que busca la activación del texto en el aquí y ahora debe ser precisa a fin de evitar navegaciones inútiles que provocan que se pierda de vista el quid de la traducción y de su recepción. En todo caso, dejando de lado a Croce, es mejor tener traducciones y, en segundo lugar, anotaciones filológicas que perderse el contenido poético de pueblos enteros.

\section{Referencias bibliográficas}

ARISTOTELIS, Ars Rhetorica. Oxford: Oxford University Press 1959.

ARISTÓteles, Tratados de lógica, I y II. Madrid: Gredos 1995.

CRESPO GÜEMES, E., «Introducción», en: HoMero, Ilíada. Madrid: Gredos 1991, 7-102.

Croce, B., Estetica come scienza dell'expressione e linguistica generale. Laterza: Bari 1928.

Diels, H. / Kranz, W. (eds.), Die Fragmente der Vorsokratiker, griechisch und deustch. Ber-

lin: Weidmannsche Buchhandlung 1903.

EschILO, Prometeo incatenato. Milano: BUR 2006.

GentiLe, G., Frammenti di estetica e i letteratura. Lanciano: Carabba 1920.

HoMero, Ilíada. Madrid: Gredos 1991.

PAz, O., Traducción: literatura y literalidad. Barcelona: Tusquets 1971.

TAPIA ZÚÑIGA, P. C., Cicerón y la translatología según Hans Josef Vermeer. México: UNAM 1996.

Vianello, P., «Notas», en: Hesíodo, Teogonía. México: UNAM 1986, I-CCCXCVI. 